\title{
Female gender is associated with dental care and dental hygiene, but not with complete dentition in the Swiss adult population
}

\author{
Paola Coda Bertea $\cdot$ Katharina Staehelin • \\ Julia Dratva $\cdot$ Elisabeth Zemp Stutz
}

Received: 20 February 2007 / Accepted: 2 May 2007 / Published online: 6 July 2007

(C) Springer-Verlag 2007

\begin{abstract}
Aim Little is known about the impact of gender on oral health, besides the influence of reproductive factors on female dentition. The aim of this study was to analyse gender differences with regard to oral health and oral health behaviour in the Swiss adult population, using data from the Swiss Health Survey of 2002.

Subjects and methods The Swiss Health Survey regularly collects detailed information on health and health determinants of a random sample of the Swiss population aged 15 years and older. A written questionnaire including items on oral health was filled in by 7,115 men and 9,026 women in 2002. Weighted prevalence rates were calculated, and multivariate logistic regression analyses used to evaluate the role of gender for complete and functional dentition and for oral health behaviour. Finally, the multivariate model was stratified for men and women and run for the outcome "complete dentition".

Results Women had a higher prevalence of visits to the dentist in the last 12 months (64\% versus $60 \%$ men), of visits to dental hygienists ( $39 \%$ versus $34 \%$ ), and of frequent tooth brushing (several times a day) (82\% versus $66 \%$ ). Adjusting for preventive behaviour, sociodemographic and socio-economic variables in multivariate analyses, female gender was positively associated with the prevalence of visits to the dentist (OR 1.33, 95\% CI 1.241.43 ) and of frequent tooth brushing several times a day (OR 2.57, 95\% CI 2.36-2.79), but not with complete dentition (OR 1.01, 95\% CI 0.93-1.09). In the stratified analysis, associations of complete dentition with socio-
\end{abstract}

P. Coda Bertea $(\triangle) \cdot K$. Staehelin $\cdot$ J. Dratva $\cdot$ E. Zemp Stutz Institute of Social and Preventive Medicine, University of Basel, Steinengraben 49 ,

4052 Basel, Switzerland

e-mail: paola.coda@unibas.ch economic status, oral hygiene and preventive behaviour were stronger in men than in women.

Conclusion Gender plays an important role in oral health. Adult women report a more pronounced preventive oral health behaviour than men; their dentition, however, is not more often complete. Mechanisms involved in women's oral health are probably more complex than those underlying men's oral health. An in-depth gender analysis is needed to shed more light upon this issue.

Keywords Gender · Oral health · Oral health behaviour

\section{Background and aim}

Oral health has important implications for the general health status (Petersen 2003; Petersen et al. 2005). Completeness of dentition influences the effectiveness of mastication, swallowing and digestion. It represents an aesthetic concern, is important in speech and may have an impact on coronary heart disease and diabetes (Grossi and Genco 1998; Hujoel et al. 2000; Hujoel et al. 2001; Janket et al. 2003).

It is known that women's oral health differs from men's: dental caries are more prevalent in women (Lukacs and Largaespada 2006), and female dentition is more often incomplete than men's (Covington 1996; Redford 1993). On the other hand women follow oral hygiene recommendations more thoroughly and draw upon more dental care (Al-Omari and Hamasha 2005; Fukai et al. 1999; Nanakorn et al. 1999; Sakki et al. 1998). Most studies report the prevalence rates for oral health indicators for women and men separately without commenting on them. Besides investigating the impact of female reproductive characteristics on oral health, other risk or protective factors have only 
rarely been investigated for women and men separately (Covington 1996; Redford 1993).

The aim of this study, therefore, was to report prevalence rates of oral health indicators and oral health behaviour in men and women, and to investigate gender differences in determinants of oral health in the Swiss adult population, using data from the 2002 Swiss Health Survey.

\section{Methods}

Data and study population

The 2002 Swiss Health Survey is the third nationwide survey conducted by the Swiss Federal Office of Statistics in intervals of 5 years. The survey assesses detailed information on health status, health care utilisation and health-related behaviour. Data were collected from a random sample of persons aged 15 years and older living in Switzerland. People were asked to participate in a telephone interview and subsequently to fill in a written questionnaire. The participation rate for the telephone interview in 2002 was $64 \%(8,909$ men and 10,797 women), and of these $82 \%$ returned the written questionnaire (7,115 men and 9,026 women). Data were then weighted for the Swiss population on the basis of age, sex, nationality and living region (Calmonte et al. 2005).

The questions on oral health considered in this paper were part of the written questionnaire. Participants reported the number of visits to the dentist and dental hygienist during the last year, the frequency of daily tooth brushing and the number of lost teeth.

Gender, the exposure of interest in this analysis, is a concept referring to the array of socially constructed roles, attitudes, behaviours and conventions for, as well as relations between and among, women and men and girls and boys (Krieger 2003). The impact of gender on oral health may act through factors such as behaviour, aesthetic concerns, available resources, or differential provider behaviour. Besides, however, biology-driven, i.e., sex-related mechanisms, such as reproductive and hormonal factors, may also be of relevance (Lukacs and Largaespada 2006). In fact, both, gender- and sex-related factors are supposedly relevant determinants of oral health. Relying on information from a health survey, we draw, however, more on social and behavioural factors. We therefore use gender as our exposure term and address the role of reproductive factors in the discussion section.

\section{Statistical analyses}

Weighted prevalence rates were calculated for 10-year age groups of women and men for the outcome variables "visit to the dentist", "visit to the dental hygienist in the last 12 months", "frequent tooth brushing" (i.e., the category "several times a day" from the question: "how often do you brush your teeth: less than once a day, once a day, several times a day?") and dentition. Dentition was specified as complete dentition (no missing teeth) and functional dentition (fewer than eight missing teeth). Furthermore, the mean number of lost teeth per subject was calculated.

Multivariate logistic regression was performed, adjusting for age, socio-economic status, nationality, living region and health-related behaviour for the following oral health outcomes: visit to the dentist during the last 12 months, frequent tooth brushing, functional dentition and complete dentition. In a second step, multivariate analysis was conducted separately for men and women for the outcome "complete dentition".

With regard to age, we first used 10-year age groups, and, secondly, 15-year age groups. In order to reduce the number of variables in the table, we display the results by 15-year age groups.

The socio-economic status was measured using variables on education and income. Participants were asked to report the highest achieved level of education. The educational status was classified into four categories: university degree, secondary school (i.e., 13 years education), compulsory school (i.e., 8 years education) and "in training or no compulsory education". The income was calculated by dividing the total household income by the number of persons living in the household. For the analysis we used the quartile groups of this variable.

Based on previous Swiss studies on oral health in Switzerland (Menghini 2000; Menghini et al. 1995), we used four categories of actual nationalities: Swiss as well as the two largest groups of non-Swiss nationalities (Italian and former Yugoslavian) and "others" (including French, Spanish, Portuguese and Turkish nationalities).

The living region was described by the level of urbanity (urban, rural) and the language area (French, German and Italian).

Preventive behaviour consisted of the smoking status (never smoker, current smoker, ex-smoker) and of an indicator for nutritional awareness (participants were asked if they are paying attention to healthy nutrition or not).

The statistical analysis was conducted using STATA/SE 8.0. Statistical significance was considered at $\mathrm{p}>0.05$.

\section{Results}

Prevalence rates of dentist visits, frequent tooth brushing, complete and functional dentition

Overall, women showed a higher prevalence of visits to the dentist (64\% vs. $60 \%)$ and to the dental hygienist compared 
to men (39\% vs. $34 \%)$. With the exception of the age groups $65-74$ and $75-84$ years, this difference was present in all age groups (Fig. 1).

The differences between men and women were even more pronounced for frequent tooth brushing: $82 \%$ of the women and $66 \%$ of the men reported brushing their teeth several times a day. This was seen in all age groups, with the highest differences in the age groups between 45 and 74 years (Fig. 2).

The mean number of lost teeth, increasing considerably for women and men with age, was similar until the age of retirement. For the age groups above 65, however, the number of lost teeth was higher in women than in men (Fig. 3).

The same pattern appears with regard to complete and functional dentition (Table 1). As for complete dentition, the prevalence rates are very similar for men and women except in the youngest age group. The same is true for functional dentition up to the age of 64 . In the elderly, however, more men have a functional dentition, while more women report that they have lost more than eight teeth. The percentage of missing information on this question increases with age and is somewhat higher in elderly women than in elderly men.

Factors associated with complete dentition

The results from multivariate analysis were consistent with those from bivariate analysis: after adjustment for sociodemographic, socio-economic and preventive behaviour variables, female gender was positively associated with visits to the dentist (OR 1.33, 95\% CI 1.24-1.43) and even more strongly with frequent tooth brushing (OR 2.57, 95\%
CI 2.36-2.79). As in bivariate analyses, gender was not associated with having a complete (OR 1.01, 95\% CI $0.93-$ 1.09 ) or with a functional dentition (OR $1.09,95 \% \mathrm{CI}$ 0.97-1.22) (Fig. 4).

To investigate whether there is a differential impact of determinants in women and men, we conducted the multivariate analyses separately for women and men. The results from this analysis are shown in Table 2. Age, nationality and education were strongly associated with complete dentition, with similar strength of associations for men and women. For both genders, age was the most important influencing factor for complete dentition. Compared to the youngest age group, already those aged 30-44 had a significantly lower probability of having complete dentition, and this probability decreased drastically in those above 45 years. Compared to Swiss participants, persons of other nationalities were less likely to have complete dentition, with little difference between men and women.

A lower educational status was associated with a lower probability of having complete dentition, again in both genders. The association was not significant for the category "in training or no secondary education", probably due to the fact that this category is heterogeneous, including persons still in training and persons without secondary education. Analogously, there is an association between income and complete dentition: the lower the income, the lower the probability of having complete dentition. This association is stronger in men than in women. Complete dentition was also less likely in women-but not in men-living in a rural region compared to those living in urban areas.

Currently smoking men and women were less likely to have complete dentition compared to never smokers. This was also seen for male ex-smokers (but not female ex-
Fig. 1 Prevalence of dentist visits (last year) by age and gender

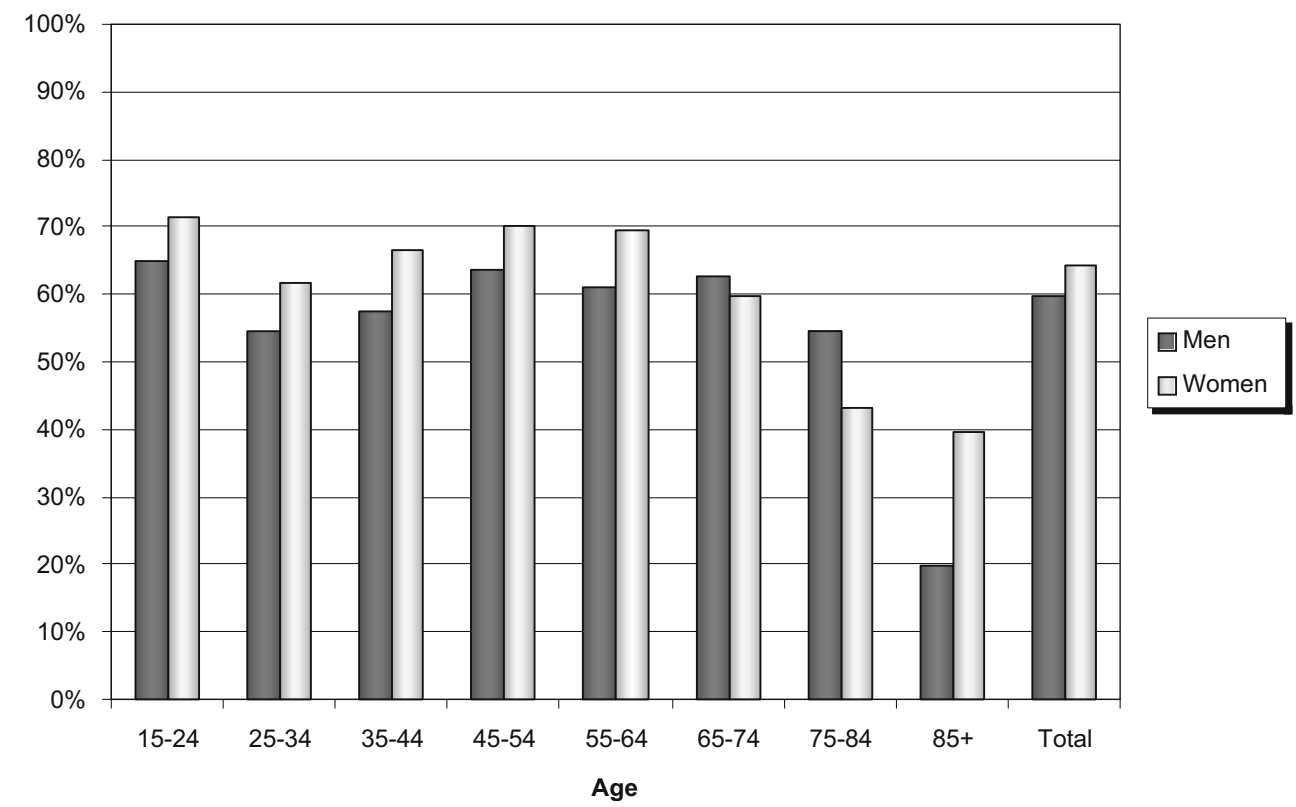


Fig. 2 Frequent tooth brushing (several times a day) by age and gender

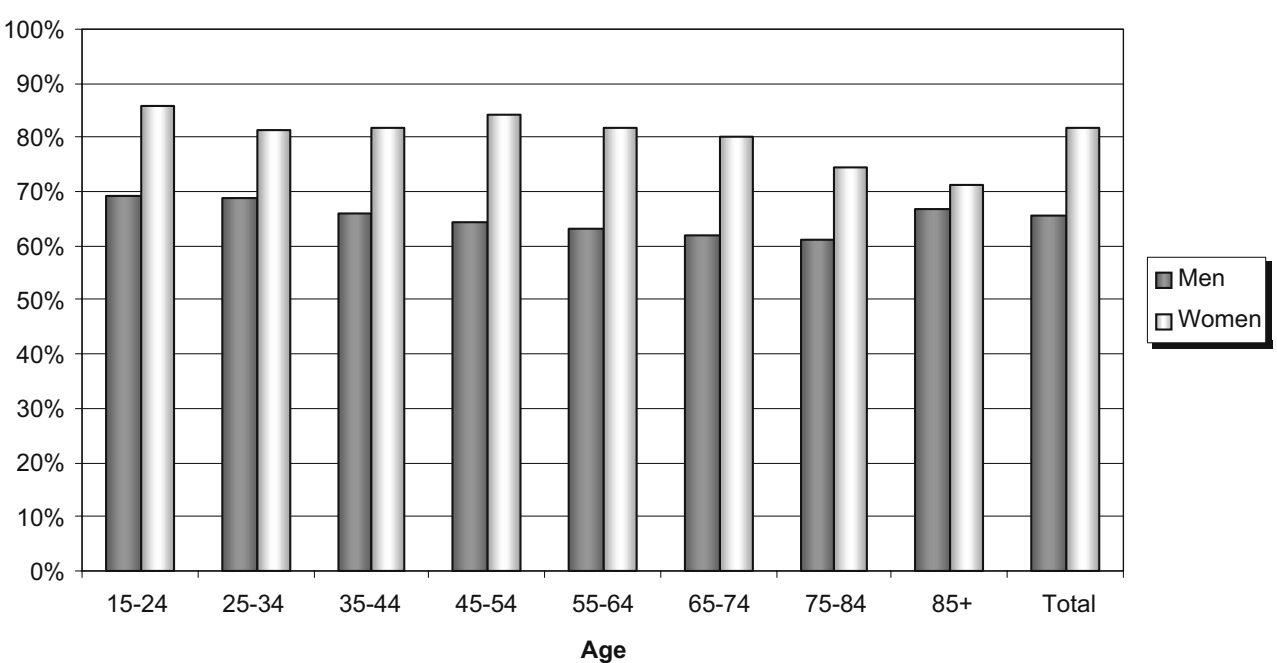

smokers). Similarly, only men with a low nutritional awareness were less likely to have complete dentition, and the association between frequent tooth brushing and complete dentition was more pronounced and significant only in men.

\section{Discussion}

Our findings highlight gender-related differences in oral health. Although adult women report a more pronounced preventive oral health behaviour than men, their dentition is less complete than men's. Furthermore, complete dentition was associated with age, education, income, nationality and current smoking in both women and men.

Our results rely on self-reported information, and we cannot exclude a recall/report bias. Based on validation studies, questionnaire-based information concerning oral status is considered to be a valid method for determining the number of remaining teeth and the use of removable dentures in the general population, but less reliable with regard to periodontal variables, yielding a fairly good agreement between the number of reported teeth and the true status (Buhlin et al. 2002; Douglass et al. 1991, Palmqvist et al. 1991; Widstrom and Nilsson 1984). However, these validation studies did not consider specific population subgroups. Most marked differences were reported for elder subjects (Buhlin et al. 2002). Given that we see the highest percentage of missing information in the elderly, this may be a concern in our study especially in the higher age groups.

Migrants who have obtained Swiss citizenship may bias the results among the Swiss towards a less favourable picture. Due to the lack of information on nationality at birth, it was not possible to take this into consideration. Since Swiss nationality is provided only after a rather long period living in Switzerland, former migrants who have obtained Swiss citizenship may take up Swiss habits. We cannot rule out, however, that we underestimate the results for the Swiss to some extent.

Higher prevalence rates of visits to the dentist and the dental hygienist were seen in women compared to men, except for the age groups of 65-74 and 75-84 years. We speculate that this may be related to a change of gender-
Fig. 3 Mean number of lost teeth by age and gender

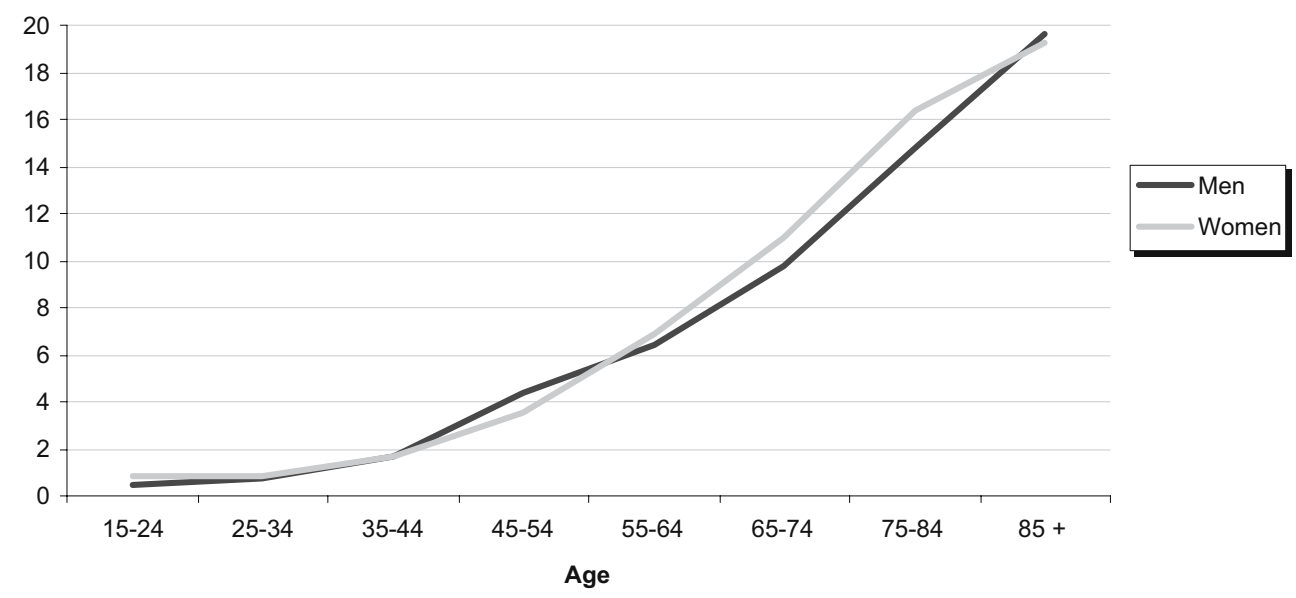


Table 1 Prevalence of complete dentition and functional dentition by age and gender

\begin{tabular}{clllll}
\hline & & $\begin{array}{l}\text { Complete } \\
\text { dentition } \%\end{array}$ & $\begin{array}{l}\text { Functional } \\
\text { dentition } \%\end{array}$ & $\begin{array}{l}>8 \text { lost } \\
\text { teeth } \%\end{array}$ & $\begin{array}{l}\text { No information } \\
\%\end{array}$ \\
\hline $15-$ & Men & 82 & 13 & 1 & 5 \\
24 years & Women & 75 & 21 & 2 & 3 \\
$25-$ & Men & 67 & 28 & 1 & 4 \\
34 years & Women & 66 & 28 & 1 & 5 \\
$35-$ & Men & 49 & 43 & 3 & 5 \\
44 years & Women & 48 & 44 & 2 & 6 \\
$45-$ & Men & 26 & 51 & 13 & 10 \\
54 years & Women & 27 & 55 & 9 & 8 \\
$55-$ & Men & 15 & 54 & 21 & 11 \\
64 years & Women & 16 & 51 & 23 & 10 \\
$65-$ & Men & 11 & 43 & 34 & 12 \\
74 years & Women & 10 & 36 & 37 & 17 \\
$75-$ & Men & 5 & 30 & 49 & 15 \\
84 years & Women & 3 & 26 & 53 & 18 \\
$>84$ years & Men & 1 & 22 & 65 & 17 \\
& Women & 2 & 18 & 64 & \\
\hline
\end{tabular}

related meanings with age (aesthetic concerns), to a lower motivation for dentist visits in elderly women with an increased number of missing teeth, or to socio-economic reasons (lower financial resources).

A differential impact of female and male gender on oral health was seen for several factors: the association of complete dentition and income was more pronounced in men. Living in a rural area was significant only for women, while former smoking, no nutritional awareness and frequent tooth brushing were significantly associated factors only for men.
The analysis yields the paradox that although women take more care of their teeth, their dentition is not better than men's. This is in line with previous findings (Al-Omari and Hamasha 2005; Covington 1996; Fukai et al. 1999; Nanakorn et al. 1999; Redford 1993; Sakki et al. 1998). Women's more pronounced dental care behaviour may be related to the fact that women are more exposed to aesthetic advertisements and more inclined to be aware of the appearance of their lips, mouths and smiles (Dzierzak 1993). In fact, cosmetic dentistry is a potential growth area. However, it does not seem to be related to complete dentition.
Fig. 4 Associations between female gender and dentist visit, frequent tooth brushing, and complete and functional dentition: Multivariate point estimates

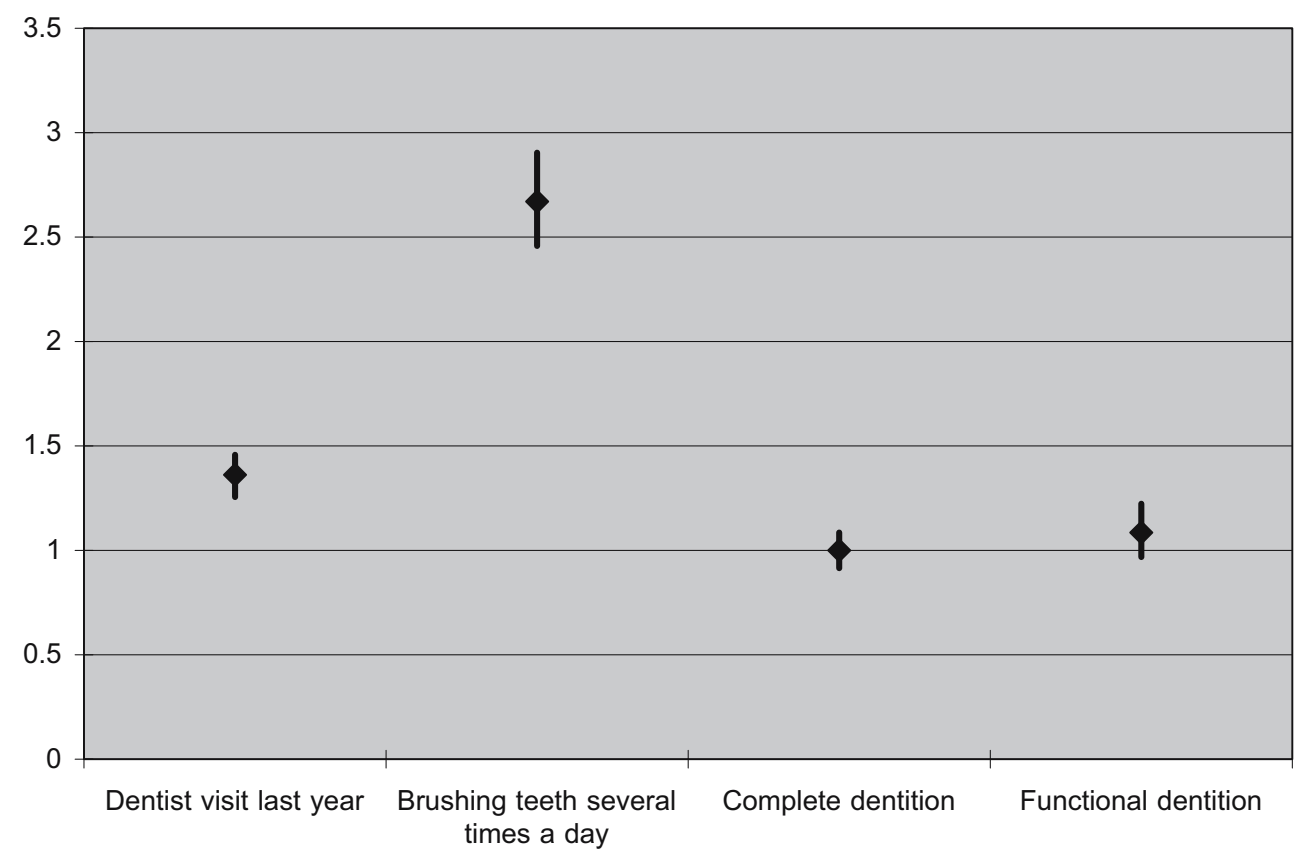


Table 2 Factors associated with complete dentition in men and women (stratified multivariate analysis)
${ }^{*} \mathrm{p}<0.05, * * \mathrm{p}<0.01$, $* * * \mathrm{p}<0.001$

\begin{tabular}{|c|c|c|}
\hline & Men $(N=6,220)$ & Women $(\mathrm{N}=7,554)$ \\
\hline & OR & OR \\
\hline \multicolumn{3}{|l|}{ Age } \\
\hline 15-29 years (ref.) & 1 & 1 \\
\hline $30-44$ years & $0.31(0.25-0.39)^{* * *}$ & $0.38(0.31-0.45)^{* * *}$ \\
\hline $45-59$ years & $0.07(0.06-0.09)^{* * *}$ & $0.09(0.07-0.11)^{* * *}$ \\
\hline $60-74$ years & $0.03(0.02-0.04)^{* * *}$ & $0.04(0.03-0.05)^{* * *}$ \\
\hline 75 years + & $0.01(0.01-0.02)^{* * *}$ & $0.01(0.00-0.01)^{* * *}$ \\
\hline \multicolumn{3}{|l|}{ Education } \\
\hline University degree (ref.) & 1 & 1 \\
\hline Secondary school & $0.69(0.60-0.79)^{* * *}$ & $0.80(0.67-0.95)^{*}$ \\
\hline Compulsory school & $0.45(0.34-0.60)^{* * *}$ & $0.38(0.29-0.48)^{* * *}$ \\
\hline In training or no secondary education & $0.68(0.37-1.28)$ & $0.74(0.46-1.20)$ \\
\hline \multicolumn{3}{|l|}{ Income } \\
\hline 1. Quartile (ref.) & 1 & 1 \\
\hline 2. Quartile & $0.78(0.66-0.92)^{* *}$ & $0.96(0.82-1.13)$ \\
\hline 3. Quartile & $0.70(0.59-0.84)^{* * *}$ & $0.85(0.73-1.00)$ \\
\hline 4. Quartile & $0.68(0.56-0.82)^{* * *}$ & $0.82(0.70-0.97)^{*}$ \\
\hline \multicolumn{3}{|l|}{ Nationality } \\
\hline Swiss (ref.) & 1 & 1 \\
\hline Italian & $0.66(0.48-0.92)^{*}$ & $0.83(0.58-1.18)$ \\
\hline Former Yugoslavia & $0.10(0.04-0.25)^{* * *}$ & $0.19(0.10-0.36)^{* * *}$ \\
\hline Other nationalities & $0.66(0.52-0.85)^{* *}$ & $0.59(0.47-0.74)^{* * *}$ \\
\hline \multicolumn{3}{|l|}{ Language area } \\
\hline German speaking (ref.) & 1 & 1 \\
\hline French speaking & $0.97(0.84-1.13)$ & $0.90(0.79-1.03)$ \\
\hline Italian speaking & $1.27(0.99-1.64)$ & $1.15(0.93-1.43)$ \\
\hline \multicolumn{3}{|l|}{ Region } \\
\hline Urban (ref.) & 1 & 1 \\
\hline Rural & $0.90(0.79-1.03)$ & $0.83(0.73-0.94)^{* *}$ \\
\hline \multicolumn{3}{|l|}{ Smoking status } \\
\hline Never smoked & 1 & 1 \\
\hline Ex-smoker & $0.76(0.65-0.89)^{* *}$ & $0.98(0.85-1.14)$ \\
\hline Current smoker & $0.70(0.61-0.81)^{* * *}$ & $0.72(0.64-0.82)^{* * *}$ \\
\hline \multicolumn{3}{|l|}{ Nutritional awareness } \\
\hline Yes (ref.) & 1 & 1 \\
\hline No & $0.87(0.76-0.99)^{*}$ & $0.97(0.85-1.12)$ \\
\hline \multicolumn{3}{|l|}{ Frequent tooth brushing } \\
\hline Yes (ref.) & 1 & 1 \\
\hline No & $0.78(0.69-0.89)^{* * *}$ & $0.92(0.79-1.07)$ \\
\hline
\end{tabular}

We saw positive associations among socio-economic status, health behaviour variables and oral health in both women and men. Younger age, Swiss nationality and higher education were protective factors of complete dentition. A higher risk of developing caries has previously been described in people with poor education or low socioeconomic status, as well as ethnic minorities, recent immigrants or elderly people (Selwitz et al. 2007).

The association among complete dentition with socioeconomic status, oral hygiene and preventive behaviour differed in strength when analysing women and men separately: the impact on oral health is more remarkable in men. Mechanisms underlying women's oral health are probably more complex than those for men's oral health. In women, additional factors may play a role, such as fluctuating hormonal levels during their life history influencing the biochemical composition of saliva and saliva flow rate (Covington 1996; Ferris 1993; Lukacs and Largaespada 2006; Steinberg 2000), and osteoporosis, which is associated with periodontal status, and may have a negative impact on retaining teeth (Covington 1996; Gera 2002; Inagaki and Noguchi 2002; Steinberg 2000; Tezal et al. 2000; von Wowern et al. 1994), or factors related to eating disorders involving vomiting and consequently increasing exposure to hydrochloric acid (Covington 1996). Unfortunately, in our data set we do not have 
sufficient information to address these issues. An additional analysis (data not shown) did not reveal an association between complete dentition and current use of oral contraception (OR 1.14, CI 0.95-1.36), nor with current use of menopausal hormonal therapy (OR 1.12, CI 0.90-1.39).

The association between dentition and urbanity observed in women may be related to their reproductive history. In fact, women living in Swiss rural areas seem to have more children and an earlier menarche than women of urban regions (Dratva et al. 2006), which could, in turn, negatively influence their dentition status. Our findings add evidence that gender plays an important role in oral health. An in-depth gender analysis would be needed to achieve a better understanding of the paradox of more pronounced oral care, but less complete dentition.

Acknowledgements We thank the Swiss Health Observatory/Federal Office of Statistics for financial support, and Manfred Neuhaus, Federal Office of Statistics, for critically reading the manuscript.

Conflict of interest statement The authors declare that there is no conflict of interest with regard to this manuscript or the research included in it.

\section{References}

Al-Omari QD, Hamasha AA (2005) Gender-specific oral health attitudes and behavior among dental students in Jordan. J Contemp Dent Pract 6(1):107-114

Buhlin K, Gustafsson A, Andersson K, Hakansson J, Klinge B (2002) Validity and limitations of self-reported periodontal health. Community Dent Oral Epidemiol 30(6):431-437

Calmonte R, Galati-Petrecca M, Lieberherr R, Neuhaus M, Kahlmeier S. Gesundheit und Gesundheitsverhalten in der Schweiz 19922002. Neuchâtel 2005

Covington P (1996) Women's oral health issues: an exploration of the literature. Probe 30(5):173-177

Douglass CW, Berlin J, Tennstedt S (1991) The validity of selfreported oral health status in the elderly. J Public Health Dent 51 (4):220-222

Dratva J, Zemp E, Städele P, Gerbase MW, Probst N, Schindler C, et al. (2006) Variability of reproductive history across the eight SAPALDIA cohort centres. European Journal of Public Health Vol. 16, Supplementum 1:159

Dzierzak J (1993) Understanding and Addressing a Women's Esthetic Needs

Ferris GM (1993) Alteration in female sex hormones: their effect on oral tissues and dental treatment. Compendium 14(12):1558 1564, 66; quiz 71

Fukai K, Takaesu Y, Maki Y (1999) Gender differences in oral health behavior and general health habits in an adult population. Bull Tokyo Dent Coll 40(4):187-193
Gera I (2002) Osteoporosis: a risk factor for periodontal disease (literature review). Fogorv Sz 95(2):49-54

Grossi SG, Genco RJ (1998) Periodontal disease and diabetes mellitus: a two-way relationship. Ann Periodontol 3(1):51-61

Hujoel PP, Drangsholt M, Spiekerman C, DeRouen TA (2000) Periodontal disease and coronary heart disease risk. Jama 284 (11):1406-1410

Hujoel PP, Drangsholt MT, Spiekerman C, DeRouen TA (2001) Periodontal disease and risk of coronary heart disease. Jama 285 (1):40-41

Inagaki K, Noguchi T (2002) Osteoporosis: a risk factor in periodontal disease. Clin Calcium 12(7):978-986

Janket SJ, Baird AE, Chuang SK, Jones JA (2003) Meta-analysis of periodontal disease and risk of coronary heart disease and stroke. Oral Surg Oral Med Oral Pathol Oral Radiol Endod 95(5):559-569

Krieger N (2003) Genders, sexes, and health: what are the connections-and why does it matter? Int $\mathrm{J}$ Epidemiol 32 (4):652-657

Lukacs JR, Largaespada LL (2006) Explaining sex differences in dental caries prevalence: saliva, hormones, and "life-history" etiologies. Am J Hum Biol 18(4):540-555

Menghini G (2000) [The dental health of Bavarian schoolchildren 1998/99, a comparison with the canton of Zurich]. Schweiz Monatsschr Zahnmed 110(7):756-757

Menghini G, Steiner M, Marthaler TM (1995) The dental status of schoolchildren from abroad in Canton Zurich 1992 to 1994. Schweiz Monatsschr Zahnmed 105(12):1529-1533

Nanakorn S, Osaka R, Chusilp K, Tsuda A, Maskasame S, Ratanasiri A (1999) Gender differences in health-related practices among university students in northeast Thailand. Asia Pac J Public Health 11(1):10-15

Palmqvist S, Soderfeldt B, Arnbjerg D (1991) Dental conditions in a Swedish population aged 45-69 years. A questionnaire study. Acta Odontol Scand 49(6):377-384

Petersen PE (2003) The World Oral Health Report 2003: continuous improvement of oral health in the 21 st century-the approach of the WHO Global Oral Health Programme. Community Dent Oral Epidemiol 31 Suppl 1:3-23

Petersen PE, Bourgeois D, Ogawa H, Estupinan-Day S, Ndiaye C (2005) The global burden of oral diseases and risks to oral health. Bull World Health Organ 83(9):661-669

Redford M (1993) Beyond pregnancy gingivitis: bringing a new focus to women's oral health. J Dent Educ 57(10):742-748

Sakki TK, Knuuttila ML, Anttila SS (1998) Lifestyle, gender and occupational status as determinants of dental health behavior. J Clin Periodontol 25(7):566-570

Selwitz RH, Ismail AI, Pitts NB (2007) Dental caries. Lancet 369 (9555):51-59

Steinberg BJ (2000) Women's oral health issues. J Calif Dent Assoc 28(9):663-667

Tezal M, Wactawski-Wende J, Grossi SG, Ho AW, Dunford R, Genco RJ (2000) The relationship between bone mineral density and periodontitis in postmenopausal women. J Periodontol 71 (9):1492-1498

von Wowern N, Klausen B, Kollerup G (1994) Osteoporosis: a risk factor in periodontal disease. J Periodontol 65(12):1134-1138

Widstrom E, Nilsson B (1984) Dental health and perceived treatment needs of Finnish immigrants in Sweden. Scand J Soc Med 12 (3):129-136 